\title{
Measuring child exposure to violence and mental health reactions in epidemiological studies: challenges and current issues
}

\author{
Criança, violência e saúde: desafios e questões atuais
}

Cristiane Seixas Duarte ${ }^{1}$

Isabel Altenfelder Santos Bordin ${ }^{2}$

Genevieve Rachel Green ${ }^{1}$

Christina W. Hoven ${ }^{1}$

${ }^{1}$ Division of Child and Adolescent Psychiatry 1051 Riverside Drive U nit \#43 New York NY 10032. duartec@

childpsych.columbia.edu

${ }^{2}$ Setor de Psiquiatria

Social, Departamento de

Psiquiatria, Escola Paulista deM edicina, Unifesp.
Abstract This paper examines challenges and current issues involved in measuring exposure to different types of violence which are associated mental health problems in children and adolescents. Standardized measures suitable for epidemiological studies, selected based on their relevance in the current literature, are briefly described and commented. The assessment of child's exposure to violence may focus on a specific event (e.g., kidnapping), a specific context (e.g., war) or even of a certain type of exposure (e.g., intrafamilial physical violence). Theassessment of child mental health after exposure to violence has traditionally focused on posttraumatic stress disorder (PTSD) - most frequently measured through nondiagnostic scales. However, other mental health re actions may be present and screening as well as diagnostic instruments which may be used to assess these reactions are also described. Two issues of emerging importance - the assessment of impairment and of traumatic grief in children - are also presented. Availability of culturally appropriate instruments is a crucial step towards proper identification of child mental health problems after exposure to violence. Key words Posttraumatic stress disorder (PTSD), Trauma, Child psychopathology, Epidemiology, M easurement, Violence
Resumo Esteartigo examina os desafios eperspectivas atuais envolvidos na mensuração da exposição a diferentes tipos de violência e problemas de saúde mental em crianças eadolescentes. Instrumentos padronizados apropriados para estudos epidemiológicos, selecionados com baseem sua relevância na literatura, são brevemente descritos e comentados. A avaliação de exposição à violência em crianças pode dizer respeito a um evento específico (como sequestro) ou um contexto específico (como guerra) ou mesmo um determinado tipo de exposição (como violência física intrafamiliar). A avaliação da saúde mental infantil após a exposição à violência tradicionalmente concentrou-se na avaliação do transtorno de estresse pós-traumático (TEPT) - freqüentemente avaliado através de escalas não- diagnósticas. Porém, outras reações psicológi cas podem ocorrer e instrumentos que podem ser usados para avaliar estas reações também são descritos neste artigo. Dois tópicos de importância emergente - a avaliação de prejuízo funcional e do pesar traumático em crianças- são também apresentados. Instrumentos culturalmente apropriados são essenciais para a identificação de problemas desaúdemental em crianças após a exposição à violência.

Palavras-chave Transtorno de estresse pós-traumático (TEPT), Trauma, Psicopatologia infantil, Epidemiologia, M ensuração, Violência 


\section{Introduction}

The assessment of children's behaviors and emotions after they had been exposed to extreme violence poses unique challenges compared to the assessment of adults. First, devel opmental stages need to be considered, as measurement strategies will most likely differ when assessing children in varying stages of development. As a general rule, the younger the child, themorelimited areour options to appropriately evaluate her or his mental health. Second, when the goal is to learn about children's reactions, different informants may berequired. The choice of the optimal informant may depend on the type of reactions of interest (internalizing or externalizing behaviors?), the age range (early childhood or adolescence?) and logistics (is it feasible to interview parents and children?).

The challenges inherent to the assessment of youth populations arecombined with thechallenges pertaining to the epidemiological measurement of psychopathology related to exposure to violence. As we know, this type of evaluation is a two-step process; including both a detailed characterization of the person's exposure as well as of the reactions possibly related to such exposure. This paper, rather than aiming to describe a large number of measures used in post-disaster contexts ${ }^{1-3}$, focus on a few selected measures which can be used to assess both exposure to traumatic events and symptoms in children which could be related to the traumatic exposure. Themeasuresincluded wereused recently in key studies addressing the impact of violence and the development of child psychopathology. Whenever a measure had already been used and/ or tested in Brazil, we included information about such use. Because our interest is learning about populations and not to conduct clinical, detailed assessments of a few individuals, we only considered measures that do not require administration by clinicians. Wefinalize the paper by calling attention to two issues we consider critical to the field: the assessment of impairment and of the emerging notion of traumatic grief in epidemiological assessments involving children.

\section{Assessment of child exposure to violence}

Determining the impact of exposureto violence on children starts with proper assessment of the degree and quality of children's exposure to possible stressors. Assessment options range from the fre quently used brief checklists to lengthy, seldom employed, detailed interviews ${ }^{4}$. Thegoal of an eval- uation may be to understand the impact of a specific event (e.g., school shooting), of a specific context (e.g., war) or even of a certain type of exposure (e.g., child sexual abuse). In some cases, the aim is to collect information about a wide range of potentially traumatic events.

Event-specific assessments ${ }^{5}$ have to be developed for each study. In these cases, the quality of thequestionsused is dependent on researchers' level of knowledge about the specific event of interest as well as the different ways it may haverepresented a threat for children 6 . After the September 11, 2001 attack to the World Trade Center, for example, it was very crucial to recognize, that even though very few children were physically present in the area, their parents were directly exposed ${ }^{7,8}$.

Instruments measuring child exposure to traumatic contexts have also been developed. Such instruments, although obviously context-dependent, can be used across different studies. In many instances, however, supplementation with questions uniqueto each particular context may be desirable. Examples are instruments addressing children's exposure to war $^{9,10}$ or community violence ${ }^{3,11,12}$.

Systematic assessment of certain types or domains of potentially traumatic events experienced by children is also frequently carried out. Children can be physically or emotionally abused or neglected. Sexual abuse is another type of child traumatic exposure. These experiences may occur as part of a specific event ${ }^{13}$ or context (war-related rape). They may be a one-time event, but in many cases abuse and neglect become part of day-to-day lives of children. The Childhood Trauma Questionnaire ${ }^{14}$ is an example of a self-administered retrospective instrument used with children asyoung as 12 years. Another example is the Conflict Tactics Scale $(\text { CTSPC })^{15}$, which can be used to gather parental and child reports of intrafamily conflict or violenceinvolving a child. A Portugueseversion of the CTSPC is available ${ }^{16}$.

In Brazil, a population-based study (BrazilSAFE) was conducted to evaluate the magnitude of different forms of intrafamilial physical violence, as part of the WorldSAFE, a multi-country project involving researchers from Brazil, Chile, Egypt, India, the Philippines, and the United States ${ }^{17}$. The pilot stage of the study ${ }^{18}$ examined a probabilistic sample of 89 children (0-17 years) and found a high prevalence of severe physical punishment $(10.1 \%)$, defined as shaking (if age $<$ or $=2$ years), kicking, choking, smothering, burning/scalding/ branding, beating, or threatening with weapon. The pilot investigation was followed by a more comprehensive assessment ${ }^{19}$. 
The WorldSAFE Core Questionnaire on Domestic Violence investigates intrafamilial violence and associated factors (original questionnaire in English developed by theWorldSAFE steering committee and copyrighted in 1998). It includes 33 items representing different child- rearing behaviors from mother and/or her husband/partner in the last 12 months. Items were partially derived from the Parent-Child Conflict Tactics Scales ${ }^{15}$ with permission from authors, and also included parental behaviors usually noted in developing countries (e.g. pulling hair, twisting ear, hitting on head with knuckles) according to clinical practice and previous WorldSAFE qualitative information (not published). The Core Questionnaire was translated to Portuguese, back translated, field tested and applied in a pilot study before being used in the full study (Brazilian version developed by Bordin IA and Paula CS in 1999).

When thereisinterest in inquiring about more than one specific event, context or domain of exposure, the instrument employed should allow the assessment of children's exposure to a wide range of events. N ew challenges arise in this situation, as decisions have to be made about the number and type of relevant exposures ${ }^{4}$. Often, the assessment of PTSD in the general population, as opposed to highly exposed groups, requires such an approach. Commonly used structured diagnostic psychiatric interviews for children which address PTSD include different lists of events which are potentially traumatic. For example, the DISC 20 includes 8 such events, the DAWBA ${ }^{15}$ lists 11 and the CAPA ${ }^{21} 17$ possible events ${ }^{22}$.

In general, very littleattention in the child trauma literature has been devoted to methodological issues involved in the evaluation of children's exposureto traumatic events. The child trauma literature has not to date provided a conceptual or empirical rationale for selecting the most important child-specific extreme events. Problems with reliability and validity of largely used checklists, which rely in broad categories when describing extreme events ${ }^{23}$, may well be exacerbated for children. It is also not clear to what extent and when parental and child reports of child exposure are necessary to characterize the exposure or in which instances one informant is better than another.

Assessment of child mental health after exposure to violence

In circumstances that involve high levels of exposure to violence, including post-disaster contexts, brevity of evaluation is frequently a major require ment ${ }^{24,25}$. Traditionally investigators have chosen to focus on posttraumatic stress reactions after disasters rather than conducting a more comprehensive assessment of child psychopathology ${ }^{26}$. Therefore, the field of child trauma has produced and repeatedly used a number of brief rating scales focused on posttraumatic stress symptoms ${ }^{3,27}$ re stricted to one specific event or context. The brevity of such scales facilitates obtaining reliability (test-retest) information. In addition, concurrent or convergent validity indicators are usually available, derived from comparisons of thescalesamong themselves, rather than to PTSD diagnosis established through clinical child psychiatric diagnostic interviews.

\section{PTSD scales}

Child PTSD has been viewed as a serious disorder in youth because of its adverse effects on biological, psychological, and social development 28,29 , as well as its debilitating course over a lifetime ${ }^{30}$.

One of the most widely used PTSD self-report scales is the Impact of Events Scale (IES) ${ }^{31}$. This scale, which was not designed specifically for children, has been simplified to be used with children 8 to 18 years ${ }^{32,33}$. Beside its questionable suitability for children, another weakness of the IES is that it was designed before the inclusion of PTSD in the DSM, therefore it does not reflect this classification. H owever, the multiple translations make this a highly used measure in international work ${ }^{34-36}$.

Another frequently used measure is the Children's Posttraumatic Stress Reaction Index $\left(\right.$ CPTSD-RI) ${ }^{37}$. The CPTSD-RI is specifically designed to measurePTSD symptomsin children and adolescents (the self report version can be administered to children as young as age 8). It does not, however, completely correspond to DSM -IV criteria. TheCPTS-RI can beadministered through selfreport and has also been translated into different languages, including Armenian ${ }^{38}$ and Cambodian ${ }^{39}$.

Filing a gap, the Child PTSD Symptom Scale (CPSS) ${ }^{40}$ is a PTSD rating scale entirely based on the DSM -IV ${ }^{41}$, but still without strong empirical support. Cartoon-based self-report measures ${ }^{42,43}$ have also been created, as an attempt to produce more developmentally appropriate instruments. M ore evidence is necessary, however, to support their psychometric properties.

We now know that the almost exclusive focus on posttraumatic stress is unjustified, as a wide 
range of reactions is observed in children after major disasters or other extreme events 8 . For those interested in taking broader approach to measure children's reactions to disasters in post-disaster contexts, the choice of what additional types of psychiatric problems should be assessed will heavily depend on the nature of the disaster.

\section{Child mental health: screening measures}

The use of screening measures to assess child psychiatric disorders can abbreviate the time taken to conduct assessments permitting a wider range of possible reactions to trauma to be considered. The Child Behavior Checklist (CBCL) ${ }^{44,45}$ is the most utilized instrument to identify mental health problems in children and adolescents worldwide. The Child Behavior Checklist - CBCL 6-1845 is a standardized parent-report screening questionnaire with 118 items to identify emotional/behavioral problems in children and adolescents at a clinical or borderline level. Data on content and construct validity, and test-retest and inter-interviewer reliability revealed adequatepsychometric properties of the instrument. I allows theidentification of empirically-based, cross-culturally reproducible ${ }^{46}$ syndromes, which can be related to the DSM classification ${ }^{47}$. The validity of a PTSD scale de rived from the $C B C L$ has not been supported 48,49 .

The CBCL 6-18 was translated to Portuguese, back translated, and field tested before achieving its final form (Brazilian version developed by Bordin IA, Paula CS and Duarte CS in 2002). On the Brazilian version of the CBCL (CBCL 4-18), initial findings from a validity study showed high sensitivity, when applied to mothers of low educational level by a trained lay interviewer. In a random sample of pediatric patients aged 4 to 12 years $(n=49)$, $80.4 \%$ of children with one or more psychiatric diagnosis based on ICD-10 were positive for be havior problems according to CBCL (total behavior problem T-score $>60)^{50}$. High sensitivity of CBCL 4-18 was also shown in a consecutive sample of children and adolescents $(n=78)$ scheduled for first appointment at the mental health outpatient clinic of the Universidade Federal do Rio de Janeiro. When comparing CBCL and K-SADS-PL results, the author noted that $82.8 \%$ of children with one or more psychiatric disorders obtained a $\mathrm{T}$-score higher than 63 in the total behavior problem scale of $\mathrm{CBCL}^{51}$.

The Strengths and Difficulties Questionnaire $(S D Q)^{52,53}$ is another general psychopathology measure, conceptually derived from the DSM classification, and originated from the Rutter Ques- tionnaires ${ }^{54}$. TheSD Q ${ }^{55}$ is a brief questionnaireused as a screening for mental health problems in children aged 4 to 16 years, and shows adequate psychometric properties. Its 25 items are distributed across five scales: anxiety and/or depression, conduct problems, hyperactivity/inattention, peer relationship problems, and prosocial behavior, with the sum of the four first scales representing total difficulties. Cutoff points determine three categories (clinical, borderline, and normal) for each of the scales. There are versions for parents/caretakers, children aged 11-18 years, and teachers. Although it does not assess PTSD specifically, it can be combined with PTSD specific scales in post-disaster assessments ${ }^{56}$. The Brazilian version of SDQ was developed by Fleitlich-Bilyk and Robert Good$\operatorname{man}^{57,58}$ and used in different studies ${ }^{59-61}$.

To assess probable mental disorders in children, another option is the DISC Predictive Scales - DPS ${ }^{62}$, a screening measure derived from the National Institute of Mental Health's Diagnostic Interview Schedulefor Children, Version IV (DISCIV) ${ }^{20}$ a structured diagnostic interview (described above). Items in the DPS were derived by secondary analysis of large data sets from studies containing DISC symptom and diagnostic information. The DPS includes only the DISC items that are most predictive of DSM -IV ${ }^{41}$ DISC diagnoses. Besides the most prevalent psychiatric disorders, including PTSD ${ }^{8}$, the DPS also contains a measure of children's impairment ( 7 global questions derived from theDISC), consistent with DSM -IV criteria ${ }^{41}$. A measure of impairment is optimally obtained in epidemiological assessments of childhood psychiatric disorders and combined with symptoms to define a probable case ${ }^{63}$.

\section{Child mental health: diagnostic measures}

Whenever possible, in order to advance knowledge in the field, studies should be able to generate more detailed information about the natureof posttraumatic stress in children. This includes, for example, levels of impairment related to observed reactions, temporal sequencing of symptoms and specificity of symptoms to the target event. Standardized diagnostic measures are a time consuming effort, which generates high quality information.

One child diagnostic interview is the Development and Well-Being Assessment (DAWBA) ${ }^{64} \mathrm{de}$ serves to bementioned. The DAWBA has theunique feature of being administered by lay interviewers, trained to record additional comments, besides the structured response. Theinterview is then reviewed by child psychiatrists, which would corroborate 
or not the diagnosis generated by computer algorithms. This procedure, which is not too labor intensive or expensive, despite being unusual in the field, does result in reliable and valid information. There is a Brazilian version of DAWBA and child psychiatric disorder prevalenceestimated based on this instrument ${ }^{65}$.

TheD iagnostic I nterview Schedulefor Children (DISC-IV) is a structured diagnostic instrument that classifies children according to DSM IV ${ }^{41}$ criteria. Symptoms (and diagnoses) are determined for last month and last year, with age of onset being ascertained for each positive diagnosis. Therecommend scoring ${ }^{66-68}$ is to use an either/or algorithm to combine parent and child information. According to this rule, a symptom is considered positive if endorsed by either informant. In order to measure sub-threshold diagnosis, the DISC PTSD module will be employed omitting a logical skip that requires a threshold of severity, ensuring that all persons complete the full PTSD symptom section. Criterion validity of the N IM H DISC-IV 69 was assessed as part of the $M$ ethods for the Epidemiology of Child and Adolescent M ental Disorders (MECA) study ${ }^{70}$. In general, the DISC showed moderate to good validity across a number of diagnoses. A part from a few notable exceptions ( $\mathrm{M}$ ajor Depressive Disorder and Separation Anxiety Disorder) the validity of youth -derived DISC diagnoses was not as good as that of the parent report. The agreement between a clinician administered DISC (using standard DISC interviewing practices) and clinician ratings, for both youth and parent versions, was generally much better than agreement between two DISC interviews on the same person separated by an interval. In general, the parent informant was more reliable than the Youth; exceptions to this were Conduct Disorder and $M$ ajor Depression. The reliability of thesymptom and criterion scales was better (often substantially) than that for most diagnoses, regardless of informant. Symptom scale reliability ranged from 0.53 to 0.87 and for all but one of the parent DISC symptom scales was excellent ${ }^{20}$. Given its high level of complexity, a paper version is not available and the DISC can only be administered as a computerized interview. TheDISC is not translated into Portuguese. Thereisa well tested and widely used Spanish translation ${ }^{71,72}$.

Another exampleworth mentioning isthe Child and Adolescent Psychiatric Assessment (CAPA). This instrument is a highly structured, interviewer-based interview that is designed for adolescents aged 9 to 17 years. Both parents and children are interviewed separately and asked about symptoms from the past three months. A diagnosis is made by combining both sets of answers according to a computer algorithm (designed to match DSM criteria). Among all the child psychiatric structured interviews, the CAPA is the interview with more published support for its PTSD module. TheCAPA lifeevents moduleissplit up into two sets of events; the "extremestressors" (as defined by the DSM ) as well as "a set of events covered by most life events scales used in the context of research on depression and anxiety." The former is often referred to as a "high magnitude" event and the later a "low magnitude" event.

\section{Functional impairment}

The challenge of systematically assessing children's mental health needs cannot beunderscored. In order to facilitatethevisualization of theimpact of violence on child mental health by the public eye, it isnecessary to makethis specific subject quantifiable, visible and understandable. Focusing on children's impaired functioning may be a good strategy, if the goal is to provide a brief indicator of child mental health which can be included as part of overall assessments of child well-being following exposure to violence.

For the most part, the DSM - IV ${ }^{41}$ and ICD $-10^{73}$ classifications require impairment for any psychiatric disorder to be diagnosed. Therefore, most of the child mental health diagnostic measures mentioned aboveask about level of impairment related to each specific disorder. Informants, however, rarely observe or report child impairment as related to specific diagnostic categories ${ }^{63}$.

Global measures are thought of as advantageous in the sense that they are short and can be scored by lay interviewers after adequate training, both characteristics conducive to research. One example of thisis the Children's Global Assessment Scale(CGAS). TheCGAS is an adaptation of DSM 's Axis V, Global Assessment of Functioning (GAF) examination ${ }^{74,75}$.

The Columbia I mpairment Scale (CIS) represents an attempt to provide a global measure of impairment which, in contrast to the CGAS, is not based on clinical judgment ${ }^{67,76}$. The CIS includes questions related to interpersonal relations, theuse of free time, and level of functioning at work or at school. Research shows that the CIS had high internal consistency coefficients, with the parent being more consistent than the child scale ${ }^{77}$. Although widely used, the CIS was criticized because it includes somequestions related to psychiatric symptoms, and not only to impaired functioning. This 
prevents the establishment of a more clear differentiation between symptoms and impairment.

One disadvantage of global impairment measures is that they do not necessarily describe the functioning of a child in different situations. Domain specific measures of impairment compartmentalize a child's functioning in areas and give each area its own score ${ }^{78}$. The Brief Impairment Scale - BIS ${ }^{79}$ includes multiple dimensions of impairment and assesses child impairment independently from symptomatology. The Child and Adolescent Functional Assessment Scale (CAFAS) includes questions regarding performance at home, school, community, thinking, behavior towards self, moods/emotions, self-harmful behavior, and substance use ${ }^{77,80-82}$. The Social Adjustment Inventory for Children and Adolescents (SAICA) ${ }^{83}$ is another comparable measure of impairment, which also inquires about indicators of functioning and symptoms. Another interesting approach is the impact supplement to the SDQ ${ }^{52}$. This supplement to the SDQ, developed in 1999, includes questions about distress, impairment, disease burden, and chronicity. These extra questions improved SDQ 's ability to discriminate between clinic and community subjects. Interestingly, the single question about impact, was significantly superior to the symptom scale to predict clinical status ${ }^{53}$.

Thelevel of functional impairment of a child is defined based on the behaviors and skills that she/ he is supposed to possess relative to other children her/his age. By measuring a child's level of impairment in relation to her/his age group, it is implied that children of a certain age should have attained a specific repertoire of skills. This, however, poses problems as adequate functioning is defined differently by distinct societies or cultures; therefore, most likely, a child who is from a different culture from the one where an impairment measure was developed would not receive an accurate score.

To avoid this potential flaw, the validity of strategies to measureimpairment should be ascertained in children of different backgrounds and cultures. While designing or evaluating the results of acrosscultural measure of child impairment, these considerations and implications must be taken into account and operationalized.

If the measurement of impairment (or disability) is restricted to clearly observable or physical characteristics, cultural influences seem not to have a strong influence on the results. The Ten Questions Screen for Childhood Disability has been used to assess disability in children cross-culturally, using a standard ten-question interview. Questions administered to parents of 2 to 9 -year old children were designed to detect both cognitive and motor disabilities; i.e., motor milestones, vision, hearing, comprehension, movement, seizures, learning, no speech, unclear speech, and slowness. Research has credited this instrument with overall good crosscultural reliability ${ }^{84}$.

Some research has been done to measure the cross-cultural adaptability of other impairment scales. The CGAS and the CIS have also been used to measure impairment in epidemiological research $^{76,85-87}$. CGAS test-retest scores obtained from Swiss children tested using the CGAS and the CIS support the cross-cultural validity of these measures ${ }^{87}$. Additionally, there is research that suggests that CAFAS may also be a measure of impairment that is relatively impervious to culture $\mathrm{r}^{81,82}$.

Bolton and Tang ${ }^{88}$ have proposed an original model to assess impairment across cultures, taking each individual society's nature into account while still preserving the cross-cultural comparability. According to this model, until today only tested in adults, different community-specific tasks are inserted into a general template and 20 to 40 respondentsin each community are presented with three questions: "What are the tasks that men/ women must do regularly to care for themselves?", "W hat are the tasks that men/women must do regularly to care for their family?", "What are the tasks that men/women must do regularly to care for their community?". After compiling the lists, the 9 most common answers, with at least one from each of the three categories, are inserted into thetemplate, in which respondents are asked to list the level of difficulty for each task. This method was tested in Rwanda and Uganda achieving satisfactory testretest reliability.

Traumatic grief: new diagnostic category?

Depending on the specific nature of the traumatic situation, it may be important to include specific reactions as part of theevaluation. Wenow know that having a family member exposed to a traumatic situation has an impact on child mental health ${ }^{7,8}$. Such impact may vary widely; and it may be particularly intense if the family member dies as a result of such exposure. Traumatic grief is a possible reaction ${ }^{89}$ to thesudden death of a loved one. Traumatic grief is not a recognized disorder in the DSM - IV, and thereforehas no widely shared agreed upon definition of symptoms and it is often confused with another newly developing diagnosis, complicated grief. Whilethese two psychiatric problems are similar, they are also distinct from one another. 
Childhood traumatic grief refers to a psychiatric condition in which a child or adolescent is unable to go through the normal grieving process following an objectively traumatic death ${ }^{89}$. Similar to PTSD, children with childhood traumatic grief will experiencehyperarousal and reexperiencing of thetraumatic event related to the loved one's death. Reexperiencing is usually triggered by trauma reminders (places, people or events that remind the child or the deceased) ${ }^{90}$. Thisindicates that thetrauma of the death is taking priority over bereavement of the death itself. According to available data, without treatment, traumatic grief could linger or worsen over time, possibly posing a serious threat for persistent impairment in social functioning ${ }^{91}$.

Children and adolescents suffering from traumatic grief can beassessed by the Inventory of Traumatic Grief (ITG) ${ }^{87}$. While there have been numerous attempts to quantify grieving, this measure has been developed specifically to measure pathologically maladaptive symptoms of grief (such as separation distress and traumatic distress). The ITG is a 30-item, self-report questionnaire originally designed for adults. The respondent's rate the degree in which their symptoms affected them within the last month on a 5-point scale (ranging from almost never to always). Other items refer to the intensity of the symptoms (ranging from no sense of bitterness to overwhelming sense of bitterness).

Interest in grief disorders are growing. Diagnostic tools have been developed attempting to separate normal (uncomplicated) grief symptoms from the unique symptoms of traumatic grief. As with many psychiatric disorders, child and adolescent populations are not being studied as thoroughly as the adult populace and this is clearly an area which deserves more attention.

\section{Final comments}

Standardized instruments are necessary for the epidemiological evaluation of child psychiatric problemsfollowing children's exposureto violence. In these circumstances, the assessment should include both a careful examination of the child's exposure to violence as well as the psychiatric problems possibly related to it. Although conditions known to be directly related to exposure to violence, such as PTSD should definitely be examined, it is also important to include other types of possible disorders, as the evidence to date suggests that there are many different ways how children can react. Although outside of the scope of this review, it has also been suggested, that depending on the nature of the disaster, it is also of major importance to assure that appropriate measurement of community-based variables is completed, as contextual elementscan bekey to understand children's psychopathological or resiliency responses. An example here would be also taking into account information about rates of violence within schools or neighborhoods, when examining individual exposure to violence among children.

The assessment of exposure to violence and psychopathology can be done with different levels of details and specificity. It is important that investigators have thegoals of theresearch project clearly established so that the best measurement strategy can be determined. The selection of instruments for the assessment of exposureto violenceand psychopathology in children will have to take into account a broad range of issues, such as disorder(s) to be measured, instrument's psychometric properties, cultural appropriateness for the specific context, length, mode of administration, possibility of drawing useful comparisons based on existing data, among others. In this paper, we provided commentaries and a description of instruments which can be valuable resources, according to our re search experience, knowledge of the literature, and evidencefrom recent studies.

The development of psychometrically sound versions of widely used instruments, which are culturally appropriate for the Brazilian context, is clearly a relevant, underway goal of the fiel $d^{92}$. It is also important, however, particularly for the assessment of exposure to violence, that experts, knowledgeable of the specific context, use their knowledge to generate context-relevant, possibly unique measures. Ideally, the development of future diagnostic classifications (e.g., DSM - V) and of other basic classification frameworks in a globalized world will more and more be informed by contexts besides those of Anglo-European countries, so that it would also include input from diverse settings, where the condition being studied (in this case violence) is highly prevalent.

Valid and reliable instruments, which can be used in different circumstances, are a crucial step to make the identification of child mental health problems easier in Brazil ${ }^{93}$, improving our capacity to understand the fine mechanism through which exposureto violenceresults in mental health problems in children, many times generating more violence. 


\section{Collaboration}

CS D uarte, IAS Bordin and CW H oven worked on the conception and writing; GR Green worked on the revision, bibliographical organization and final draft of this paper.

\section{References}

1. Balaban V. Psychological assessment of children in disasters and emergencies. Disasters 2006; 30 (2):178-198.

2. Strand VC, Sarmiento TL, Pasquale LE. Assessment and screening tools for trauma in children and adolescents: a review. Trauma Violence Abuse 2005; 6(1):55-78.

3. Ohan JL, Myers K, Collett BR. Ten-year review of rating scales. IV: scales assessing trauma and its effects. J Am Acad Child Adolesc Psychiatry 2002; 41(12):1401-1422.

4. Grant KE, Compas BE, Thurm AE, M CMahon SD, Gipson PY. Stressors and child and adolescent psychopathology: Measurement issues and prospective effects. J Clin Child Adolesc Psychol 2004; 33:412-425.

5. Pynoos RS, Frederick C, Nader K, Arroyo W, Steinberg A, Eth S. Life threat and posttraumatic stress in schoolage children. Arch Gen Psychiatry 1987; 44(12):10571063.

6. Pfefferbaum B, Nixon SJ, Krug RS, Tivis RD, Moore VL, Brown JM. Clinical needs assessment of middle and high school students following the 1995 Oklahoma City bombing. Am J Psychiatry 1999; 156(7):1069-1074.

7. Duarte CS, Hoven CW, Wu P, Cotel S, Mandell DJ, Nagasawa M. Posttraumatic stress disorder in children with first responders in their families. J Trauma Stress 2006; 19(2):301-306.

8. Hoven CW, Duarte CS, Lucas CP, Wu P, Mandell DJ, Goodwin RD. Psychopathology among N ew York City public school children six months after September 11. Arch Gen Psychiatry 2005; 62:545-552.

9. Yule W. Theory, training and timing: Psychosocial interventions in complex emergencies. Int Rev Psychiatry 2006; 18(3):259-264.

10. Macksoud $M$. Assessing war trauma in children: A case study of Lebanese children. J Refug Stud 1992; 5(1):1-15.

11. Cooley MR, Turner SM, Beidel DC. Assessing community violence: the children's report of exposure to violence. J Am Acad Child Adolesc Psychiatry 1995; 34(2):201208.

12. Richters JE, Martinez P. The NIMH community violence project: I. Children as victims of and witnesses to violence. Psychiatry 1993; 56(1):7-21.

13. Molnar BE, Buka SL, Kessler RC. Child Sexual Abuse and Subsequent Psychopathology: Results from the National Comorbidity Survey. Am J Public Health 2001; 91(5):753-760.

14. Bernstein DP, Ahluvalia T, Pogge D, Handelsman L. Validity of the Childhood Trauma Questionnaire in an adolescent psychiatric population. J Am Acad Child Adolesc Psychiatry 1997; 36(3):340-348.

15. traus M A, Hamby SL, Finkelhor D, M oore DW, Runyan D. Identification of child maltreatment with the ParentChild Conflict Tactics Scales: development and psychometric data for a national sample of American parents. Child Abuse Negl 1998; 22(4):249-270.
16. Reichenheim ME, M oraes CL. Psychometric properties of the Portuguese version of the Conflict Tactics Scales: Parent-child Version (CTSPC) used to identify child abuse. Cad Saúde Pública 2006; 22(3):503-515.

17. Sadowski LS, Hunter WM, Bangdiwala SI, M unoz SR. The world studies of abuse in the family environment (WorldSAFE): a model of a multi-national study of fam-

18. ily violence. Inj Control Saf Promot 2004; 11(2):81-90. Bordin IAS, Paula CS, do Nascimento R, Duarte CS. Severe physical punishment and mental health problems in an economically disadvantaged population of children and adolescents. Rev Bras Psiquiatr. 2006; 28(4):290-296.

19. Bordin I, Duarte CS, Peres CA, Nascimento R, Curto BM, Paula CS. Severe Physical Punishment: Risk for Mental Health Problems in Urban Poor Brazilian Children A Cross-Sectional Study. Bulletin of the World Health Organization. In press.

20. Shaffer D, Fisher $P$, Lucas $C P$, Dulcan $M K$, SchwabStone ME. NIMH Diagnostic Interview Schedule for Children Version IV (NIMH DISC-IV): Description, differences from previous versions, and reliability of some common diagnoses. J Am Acad Child Adolesc Psychiatry 2000; 39(1):28-38.

21. Angold A, Costello EJ. The Child and Adolescent Psychiatric Assessment (CAPA). J Am Acad Child Adolesc Psychiatry 2000; 39(1):39-48.

22. Costello EJ, Angold A, M arch J, Fairbank J. Life events and post-traumatic stress: the development of a new measure for children and adolescents. Psychol M ed. 1998; 28(6):1275-1288.

23. Dohrenwend BP. Inventorying stressful life events as risk factors for psychopathology: Toward resolution of the problem of intracategory variability. Psychol Bull. 2006; 132(3):477-495.

24. Winston FK, Kassam-Adams N, Garcia-Espana F, Ittenbach R, Cnaan A. Screening for risk of persistent posttraumatic stress in injured children and their parents. JAM A 2003; 290(5):643-649.

25. Comer JS, Kendall PC. Terrorism: The psychological impact on youth. Clin Psychol: Science and Practice 2007; 14(3):179-212.

26. Hoven CW, Mandell D, Duarte CS, Wu P, Giordano V. An epidemiological response to disaster: The post-9/11 psychological needs assessment of New York City public school students. In: Neria Y, Gross R, Marshall R, editors. 9/11: M ental Health in the Wake of Terrorist Attacks. New York: Cambridge University Press; 2006. p. 71-94.

27. Hawkins S, Radcliffe J. Current measures of PTSD for children and adolescents. J Pediatr Psychol 2006; 31(4):420-430. 
28. Pfefferbaum B. Posttraumatic stress disorder in children: a review of the past 10 years. J Am Acad Child Adolesc Psychiatry 1997; 36(11):1503-1511.

29. Pynoos RS. Posttraumatic stress disorder: a clinical review. Lutherville, M D: The Sidran Press; 1994.

30. Udwin O, Boyle S, Yule W, Bolton D, O'Ryan D. Risk factors for long-term psychological effects of a disaster experienced in adolescence: Predictors of post traumatic stress disorder. J Child Psychol Psychiatry 2000; 41(8):969-979.

31. Horowitz M, Wilner N, Alvarez W. Impact of Event Scale - M easure of Subjective Stress. Psychosom M ed. 1979; 41(3):209-218.

32. Smith P, Perrin S, Yule W, Rabe-H esketh S. War exposure and maternal reactions in the psychological adjustment of children from Bosnia-Hercegovina. J Child Psychol Psychiatry 2001; 42(3):395-404.

33. Sack WH, Seeley JR, Him C, Clarke GN. Psychometric properties of the Impact of Events Scale in traumatized Cambodian refugee youth. Pers Individ Dif. 1998; 25(1):57-67.

34. Schwarzwald J, Solomon Z, Weisenberg M, Mikulincer $M$. Validation of the Impact of Event Scale for Psychological Sequelae of Combat. J Consult Clin Psychol. 1987; 55(2):251-256.

35. Brom D, Kleber R, Defares P. Brief Psychotherapy for Posttraumatic Stress Disorders. J Consult Clin Psychol. 1989; 57(5):607-612.

36. Wu K, Chan K. The development of the Chinese version of Impact of Event Scale - Revised (CIES-R). Soc Psychiatry Psychiatr Epidemiol. 2003; 38:94-98.

37. Steinberg AM, Brymer MJ, Decker KB, Pynoos RS. The University of California at Los Angeles Post-traumatic Stress Disorder Reaction Index. Curr Psychiatry Rep. 2004; 6(2):96-100.

38. Goenjian AK, Pynoos RS, Steinberg AM, Najarian LM, Asarnow JR, Karayan I. Psychiatric comorbidity in children after the 1988 earthquake in Armenia. J Am Acad Child Adolesc Psychiatry 1995; 34(9):1174-1184.

39. Realmuto GM, Masten A, Carole LF, Hubbard J, Groteluschen A, Chhun B. Adolescent Survivors of Massive Childhood Trauma in Cambodia - Life Events and Current Symptoms. J Trauma Stress 1992; 5(4):589-599.

40. Foa EB, Johnson KM, Feeny NC, Treadwell KR. The child PTSD Symptom Scale: a preliminary examination of its psychometric properties. J Clin Child Psychol 2001; 30(3):376-384

41. American Psychiatric Association. Diagnostic and Statistical Manual of Mental Disorders. $4^{\text {th }}$ ed. Washington, D.C.: American Psychiatric Association; 1994.

42. Praver F, DiGiuseppe R, Pelcovitz D, M andel FS, Gaines R. A preliminary study of a cartoon measure for children's reactions to chronic trauma. Child Maltreatment 2000; 5(3):273-285.

43. Geller PA, Neugebauer R, Possemato AK, Walter $P$, Dummit ES, III, Silva RR. Psychometric Properties of Darryl, a Cartoon Based M easure to Assess Community Violence-Related PTSD in Children. Psychiatr Q. 2007; 78(2):157-168.

44. Achenbach TM. Manual for the Child Behavior Checklist/4-18 and 1991 profile. Burlington, VT: Department of Psychiatry, University of Vermont; 1991.

45. Achenbach TM, Rescorla LA. M anual for the ASEBA school-age forms \& profiles. Burlington, VT; U niversity of Vermont, Research Center for Children, Youth $\&$ Families; 2001.
46. Ivanova MY, Achenbach TM, Dumenci $L$, Almqvist $F$, Weintraub S, Bilenberg N. Testing the 8-syndrome structure of the child behavior checklist in 30 societies. J Clin Child Adolesc Psychol 2007; 36(3):405-417.

47. Achenbach TM, Dumenci L, Rescorla LA. DSM-oriented and empirically based approaches to constructing scales from the same item pools. J Clin Child Adolesc Psychol 2003; 32(3):328-340.

48. Ruggiero KJ, MCLeer SV. PTSD scale of the Child Behavior Checklist: concurrent and discriminant validity with non-clinic-referred sexually abused children. J Trauma Stress 2000; 13(2):287-299.

49. Sim L, Friedrich WN, Davies WH, Trentham B, Lengua $\mathrm{L}$, Pithers W. The Child Behavior Checklist as an indicator of posttraumatic stress disorder and dissociation in normative, psychiatric, and sexually abused children. J Trauma Stress 2005; 18(6):697-705.

50. Bordin IAS, Mari JJ, Caeiro M F. Validação da versão brasileira do 'Child Behavior Checklist' (CBCL) - Inventário de Comportamentos da Infância e da Adolescência: dados preliminares. Revista da Associação Brasileira de Psiquiatria 1995; 17(2):55-66.

51. Brasil HH. Desenvolvimento da versão brasileira da KSADS-PL [Schedule for affective disorders and schizophrenia for school aged children present and lifetime version] $e$ estudo de suas propriedades psicométricas. São Paulo: Escola Paulista de M edicina, Universidade Federal de São Paulo; 2003.

52. Goodman R. The Strengths and Difficulties Questionnaire: A research note. J Child Psychol Psychiatry 1997; 38:581-586.

53. Goodman R, Scott S. Comparing the Strenghts and Difficulties Questionnaire and the Child Behavior Checklist: Is small beaultiful? J Abnorm Child Psychol 1999; 27:17-24.

54. Rutter M. A children's behavior questionnaire for completion by teachers: preliminary findings. Journal of Child Psychology and Psychiatry 1967; 8:1-11.

55. Goodman R. Psychometric properties of the strengths and difficulties questionnaire. J Am Acad Child Adolesc Psychiatry 2001; 40(11):1337-1345.

56. M CDermott BM, Lee EM, Judd M, Gibbon P. Posttraumatic stress disorder and general psychopathology in children and adolescents following a wildfire disaster. Can J Psychiatry 2005; 50(3):137-143.

57. Fleitlich-Bilyk B. The prevalence of psychiatric problems in 7-14-year olds in the southeast of Brazil. London: De partment of Child and Adolescent Psychiatry, Institute of Psychiatry, King's College, London University; 2002.

58. Fleitlich BW, Cortazar PG, Goodman R. Questionário de Capacidades e Dificuldades (SDQ). Infanto 2000; 8:44-50.

59. Woerner W, Fleitlich-Bilyk B, Martinussen R, Fletcher J, Cucchiaro G, Dalgalarrondo P. The Strengths and Difficulties Questionnaire overseas: Evaluations and applications of the SDQ beyond Europe. Eur Child Adolesc Psychiatry 2004; 13(2):47-54.

60. Fleitlich-Bilyk B, Goodman R. Social factors associated with child mental health problems in Brazil: Cross sectional survey. BMJ 2001; 323(7313):599-600.

61. Cury C, Golfeto JH. Strengths and difficulties questionnaire (SDQ) a study of school children in Ribeirao Pre to. Rev Bras Psiquiatr. 2003; 25(3):139-145. 
62. Lucas $C P$, Zhang HY, Fisher PW, Shaffer D, Regier DA, Narrow WE. The DISC Predictive Scales (DPS): Efficiently screening for diagnoses. J Am Acad Child Adolesc Psychiatry 2001; 40(4):443-449.

63. Bird HR, Davies M, Fisher P, Narrow WE, Jensen PS, Hoven CW. How specific is specific impairment? J Am Acad Child Adolesc Psychiatry 2000; 39(9):1182-1189.

64. Goodman R, Ford T, Richard H, Gatward R, M eltzer H The Development and Well-Being Assessment: Description and initial validation on an integrated assessment of child and adolescent psychopathology. J Child Psychol Psychiatry 2000; 41:645-655.

65. Fleitlich-Bilyk B, Goodman R. Prevalence of child and adolescent psychiatric disorders in southeast Brazil. J Am Acad Child Adolesc Psychiatry 2004; 43(6):727-734.

66. Bird HR, Gould MS, Staghezza B. Aggregating data from multiple informants in child psychiatry epidemiological research. J Am Acad Child Adolesc Psychiatry 1992; 31(1):78-85.

67. Gould MS, Bird H, Jaramillo BS. Correspondence be tween statistically derived behavior problem syndromes and child psychiatric diagnoses in a community sample. J Abnorm Child Psychol. 1993; 21(3):287-313.

68. Piacentini J, Shaffer D, Fisher P, Schwab-Stone M, Davies M, Gioia P. The Diagnostic Interview Schedule for Children-Revised Version (DISC-R): III. Concurrent criterion validity. J Am Acad Child Adolesc Psychiatry 1993; 32(3):658-665.

69. Schwab-Stone ME, Shaffer D, Dulcan MK, Jensen PS, Fisher P, Bird HR. Criterion validity of the NIMH Diagnostic Interview Schedule for Children Version 2.3 (DISC-2.3). J Am Acad Child Adolesc Psychiatry 1996; 35(7):878-888.

70. Lahey BB, Flagg EW, Bird HR, Schwab-Stone ME, Canino G, Dulcan MK. The NIMH M ethods for the Epidemiology of Child and Adolescent M ental Disorders (MECA) Study: background and methodology. J Am Acad Child Adolesc Psychiatry 1996; 35(7):855-864.

71. Bravo M, Woodbury-Farina M, Canino G, Rubio-Stipec M. The Spanish translation and cultural adaptation of the Diagnostic Interview Schedule for Children (DISC) in Puerto Rico. Cult M ed Psychiatry 1993; 17(3):329-344.

72. Bird HR, Canino GJ, Davies M, Duarte CS, Febo V, Ramirez R. A study of disruptive behavior disorders in Puerto Rican youth: I. Background, design, and survey methods. J Am Acad Child Adolesc Psychiatry 2006; 45(9):1032-1041.

73. WH O. International classification of diseases. $10^{\text {th }}$ ed. Geneva: WHO; 1992.

74. Bird HR. The assessment of functional impairment. In: Shaffer D, Lucas CP, Richters JE, editors. Diagnostic assessment in child and adolescent psychopathology. New York: The Guilford Press; 1999. p. 209-229.

75. Shaffer D, Gould MS, Brasic J, Ambrosini P, Fisher $P$, Bird H. A children's global assessment scale (CGAS). Arch Gen Psychiatry 1983; 40(11):1228-1231.

76. Bird HR, Schwab-Stone M, Andrews H, Goodman SH, Dulcan $M$, Richters J. Global measures of impairment for epidemiologic and clinical use with children and adolescents. Int J M ethods Psychiatr Res.1996; 6:295-307.

77. American Psychiatric Association. Task Force for the $\mathrm{H}$ andbook of Psychiatric M easures. Handbook of Psychiatric M easures. $1^{\text {st }}$ ed. Washington, D.C.: American Psychiatric Association; 2000.
78. Frank SJ, Paul JS, M arks M, Van Egeren LA. Initial validation of the functional impairment scale for children and adolescents. J Am Acad Child Adolesc Psychiatry 2000; 39(10):1300-1308.

79. Bird HR, Canino G, Davies M, Ramirez R, Chavez L, Duarte CS. The Brief Impairment Scale (BIS): A multidimensional scale of functional impairment for children and adolescents. J Am Acad Child Adolesc Psychiatry 2005; 44(7):699-707.

80. 80. Hodges K, Wotring J. Client typology based on functioning across domains using the CAFAS: implications for service planning. J Behav Health Serv Res. 2000; 27(3):257-270.

81. Bates MP. The Child and Adolescent Functional Assessment Scale (CAFAS): review and current status. Clin Child Fam Psychol Rev. 2001; 4(1):63-84.

82. Hodges K, Wong M M. Psychometric characteristics of a multidimensional measure to assess impairment: The Child and Adolescent Functional Assessment Scale. J Child Fam Stud. 1996; 5(4):445-467.

83. John K, Gammon GD, Prusoff BA, Warner V. The Social Adjustment Inventory for Children and Adolescents (SAICA): testing of a new semistructured interview. J Am Acad Child Adolesc Psychiatry 1987; 26(6):898-911.

84. Durkin MS, Wang W, Shrout PE, Zaman ZM, Hasan $Z M$, Desai P. Evaluating a ten questions screen for childhood disability: reliability and internal structure in different cultures. J Clin Epidemiol. 1995; 48(5):657-666.

85. Canino GJ, Costello EJ, Angold A. Assessing functional impairment and social adaptation for child mental health services research: a review of measures. $\mathrm{M}$ ent $\mathrm{H}$ ealth Serv Res.1999; 1(2):93-108.

86. Bird HR, Canino G, Rubio-Stipec M, Ribera JC. Further measures of the psychometric properties of the Children's Global Assessment Scale. Arch Gen Psychiatry 1987; 44(9):821-824.

87. Steinhausen HC, M etzke CW. Global measures of impairment in children and adolescents: results from a Swiss community survey. Aust N Z J Psychiatry 2001; 35(3):282-286.

88. Bolton P, Tang AM . An alternative approach to crosscultural function assessment. Soc Psychiatry Psychiatr Epidemiol. 2002; 37(11):537-543.

89. Prigerson $H$, Shear MK, Jacobs SC, Reynolds CF, Maciejewski PK, Davidson JR. Consensus criteria for traumatic grief. A preliminary empirical test. $\mathrm{Br}$ J Psychiatry 1999; 174:67-73.

90. Pynoos RS, Nader K. Childrens Exposure to Violence and Traumatic Death. Psychiatric Annals 1990; 20(6):334-344.

91. Boelen PA. Cognitive-behavioral therapy for complicated grief: Theoretical underpinnings and case descriptions. Journal of Loss \& Trauma 2006; 11(1):1-30.

92. Duarte CS, Hoven CW, Berganza C, Bordin I, Bird H, $M$ iranda CT. Child mental health in Latin America: present and future epidemiologic research. Int J Psychiatry $M$ ed. 2003; 33(3):203-222.

93. Duarte CS, Bordin IAS. Instrumentos de avaliação na área de saúde mental da infância. Rev Bras Psiquiatr. 2000; 22(Supl. 2): SII55-SII58.

Artigo apresentado em 19/12/2008

Aprovado em 03/06/2008

Versão final apresentada em 25/09/2008 